\title{
Design of an Electric Machine Integrated with Trans-Rotary Magnetic Gear
}

\author{
Siavash Pakdelian, Member, IEEE, Yateendra Deshpande, Member, IEEE, and Hamid A. Toliyat, \\ Fellow, IEEE
}

\begin{abstract}
Design aspects of the trans-rotary magnetic gear (TROMAG) integrated rotary machine are discussed in this paper with particular focus on optimizing system cost and weight. Analytical models are used for design of the TROMAG. Optimal designs of the rotary machine are found by using a population based genetic algorithm and two dimensional (2D) finite element analysis (FEA) and thermal considerations. Weight, volume, and cost of the resultant system are then compared with the Paretooptimal set of a permanent magnet linear tubular machine (LTM) that is designed for the same force and speed specification. It is shown in this paper that, for high-force, low-speed reciprocating motion applications, an electromechanical motion system consisting of a TROMAG and a rotary electric machine can far surpass a conventional direct drive linear machine in terms of weight, volume, and initial and operating cost.
\end{abstract}

Index Terms-- Magnetic gear, Trans-Rotary magnetic gear, Linear PM machines, Finite element analysis.

\section{NOMENCLATURE}

$G \quad$ TROMAG's gear ratio

$P \quad$ TROMAG's number of poles

$L_{a} \quad$ TROMAG's active length

$\tau_{P} \quad$ Pole pitch (for TROMAG and LTM)

$w \quad$ Magnet width (for TROMAG and LTM)

$h_{M}$ Magnet thickness (for TROMAG, IPM, and LTM)

$\alpha \quad$ Magnet coverage (for TROMAG and LTM)

$R_{m} \quad$ Outer radius of inner part (for ROMAG and LTM)

$R_{r i} \quad$ IPM's Rotor inner radius

$R_{r o}$ IPM's rotor outer radius

$S R$ IPM's ratio of stator outer radius to rotor outer radius

$d_{c s} \quad$ Stator core thickness (for IPM and LTM)

$d_{c t}$ LTM's translator core thickness

$W_{t} \quad$ Tooth width (for IPM and LTM)

$b_{0} \quad$ Slot opening (for IPM and LTM)

$H_{S O}$ Slot tip height (for IPM and LTM)

$H_{S I}$ Slot wedge height (for IPM and LTM)

$t_{b} \quad$ Bridge thickness of IPM

$J$ Conductor current density (for IPM and LTM)

$N_{S} \quad$ IPM's number of slots

S. Pakdelian is with the Department of Electrical and Computer Engineering, University of Illinois at Chicago, IL 60607, USA (email: spakdel@uic.edu).

Y. Deshpande and H. A. Toliyat are with the Department of Electrical and Computer Engineering, Texas A\&M University, College Station, TX 77843, USA (e-mail: yateendra@email.tamu.edu, toliyat@tamu.edu).

\author{
$N_{P} \quad$ IPM's number of poles \\ $V_{\text {tot }} \quad$ Total volume (for TROMAG, IPM, and LTM) \\ $M_{a} \quad$ Active mass (for TROMAG and LTM) \\ $M_{\text {stroke }}$ Extra mass due to stroke (for TROMAG and LTM) \\ $M_{\text {tot }}$ Total mass (for TROMAG, IPM, and LTM) \\ $C_{a} \quad$ Cost of active material (for TROMAG and LTM) \\ $C_{m} \quad$ IPM's cost of material \\ $C_{\text {stroke }}$ Cost of stroke material (for TROMAG and LTM) \\ $C_{e}$ Cost of electricity over 5 years (for TROMAG, IPM, \\ and LTM) \\ $C_{\text {tot }}$ Total cost of material and electricity (for TROMAG, \\ IPM, and LTM) \\ $T_{\text {spot }} \quad$ Slot hot spot temperature (for IPM and LTM)
}

\section{INTRODUCTION}

$\mathrm{T}$ HE last decade has witnessed intense interest in integrating magnetic gears and electric machines to achieve machine configurations that offer high torque density and high power factor. It was, in fact, the emergence of high torque density field-modulated magnetic gears that paved the way for development of the gear-integrated machines. These gears generally consist of a set of ferromagnetic pole pieces inserted between two concentric rotors that have different number of permanent magnet (PM) poles. While the inner rotor has a low number of poles and operates at high speed and low torque, the outer rotor with high number of poles operates at high torque and low speed $[1,2]$.

The first proposed gear-integrated machine topologies were radial flux rotary systems that either inserted the stator inside the high speed rotor [3] or added the stator as the outermost layer of the system [4]. It was shown that these systems could offer torque densities roughly twice as the conventional PM machines while maintaining high power factors. The applications that propelled the research on the rotary gearintegrated machines were mainly electric traction $[3,5]$ and wind turbines $[6,7]$.

Later, high-force, low-speed linear motion applications stimulated the researchers to propose linear counterparts of the rotary gear-integrated machines mentioned above. A linear gear-integrated generator was investigated in [8] for a freepiston engine application and in [9] and [10] for wave energy conversion application. The proposed linear systems, similar to their rotary configurations, were able to offer roughly twice the force density of a PM linear machine. 
Recently, another approach has been taken on to address the problem of designing an electric machine for low speed reciprocating motion applications more effectively. To design a generator, the idea is to first convert the low speed linear motion of the prime mover to high speed rotation, and then use a high speed rotary generator. The conversion can be performed by a mechanical roller screw system. Such a system, although offering high force density, would suffer from high friction due to direct mechanical contact between sliding parts and, therefore, low reliability. In addition, the mechanical contact would require proper lubrication at all times and necessitate regular maintenance. As such, a contactfree force transmission system would be preferable for applications that mandate low maintenance and high reliability. Conversion of linear motion to high speed rotation through magnetic field seems to have been first proposed in [11]. The idea has recently attracted attention for applications such as wave energy conversion [12, 13] and force-dense actuators [14].

The magnetic device that performs the conversion of highforce, low-speed linear motion to low-torque, high-speed rotation is referred to as the trans-rotary magnetic gear (TROMAG) [15]. Different views of a TROMAG are depicted in Fig. 1. A TROMAG consists of two cylindrical parts that are ideally concentric: a translator moving back and forth along its central axis and a rotor rotating about the same axis. Both rotor and translator are made of ferromagnetic iron cores lined with helically shaped alternating PM poles. Although in Fig. 1 the inner part is identified as the rotor, depending on the application the mechanical assembly can be arranged such that the inner part plays the role of the translator. In both cases, either the rotor or translator has to be longer than the other to allow magnetic engagement of the two parts while the translator reciprocates. In this paper, the length of the shorter part is called the active length, and the total difference between the lengths of the two parts is referred to as the "stroke". The same terms will be used for the LTM in which either the stator or the translator has to be longer than the other part. Moreover, the maximum axial force a TROMAG can develop, which depends on the dimensions and materials used, is called pullout force in analogy with synchronous machines [15]. The pull-out force per active air gap area, the area that is enclosed

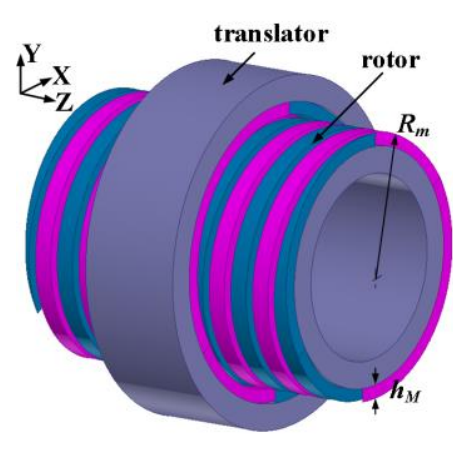

(a)

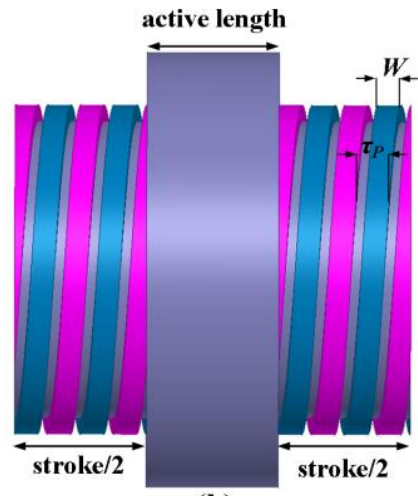

(b)
Fig. 1. Views of an idealized TROMAG; (a) 3D view; (b) side view. between the rotor and translator, is referred to as the shear stress of a TROMAG.

Gear ratio of TROMAG, $G$, can be defined as the ratio of translator force, $F_{t}$ to the rotor torque, $T_{r}$ and equals:

$G=F_{t} / T_{r}=2 \pi /\left(P \tau_{P}\right)$

in which $P$ is the number for poles as viewed from the $\mathrm{XY}$ plane (2 poles in Fig. 1), and $\tau_{P}$ is the pole pitch along the $\mathrm{Z}$ axis.

A TROMAG can be used in both motoring mode and generating mode drive trains. In a generating mode of operation, for example when a TROMAG is used along with a buoy as its prime mover, the TROMAG's translator is coupled to the floating part of the buoy and moves up and down with ocean waves at low speed. As a result of the translator motion, the rotor that is coupled to a rotary generator rotates at high speed. For motoring operation, when a TROMAG is used to propel a translating load, the TROMAG's rotor is driven by a high speed rotary motor that is coupled to it. As a result, the TROMAG's translator, which is coupled to the load, moves at low speed and propels the load. The schematic of a TROMAG set-up assembly is shown in Fig. 2, in which a short outer translator and a long inner rotor are used. The translator is press-fit into a cubical flange that is mounted on linear bearings sliding on rails. To be able to couple the translator to a load, an end-flange is provided that is connected to the main translator flange by means of two rods. The rotor is held at its two ends by rotary ball bearings, and is coupled to a rotary electric machine through a torque transducer. The actual testbed is presented in Fig. 3, where a PM LTM (with a significantly lower force rating) is coupled to the translator through a force transducer. A zoomed-in view of the prototyped TROMAG is shown in Fig. 4. The translator is fully covered by magnets but the rotor is covered partially.

Principles of operation of the TROMAG [15] and its magnetic design [16-18] have been presented in earlier publications. This paper aims to show that for high-force, lowspeed load characteristic, the proposed approach; that is, integrating a TROMAG and a rotary machine, which hereafter is referred to as MITROMAG for the ease of reference, can

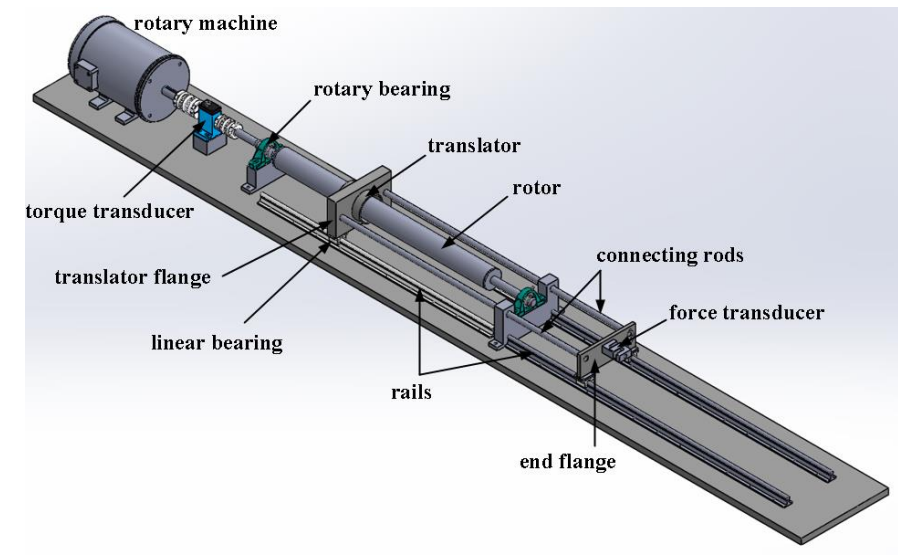

Fig. 2. Schematic of a TROMAG set-up assembly. 


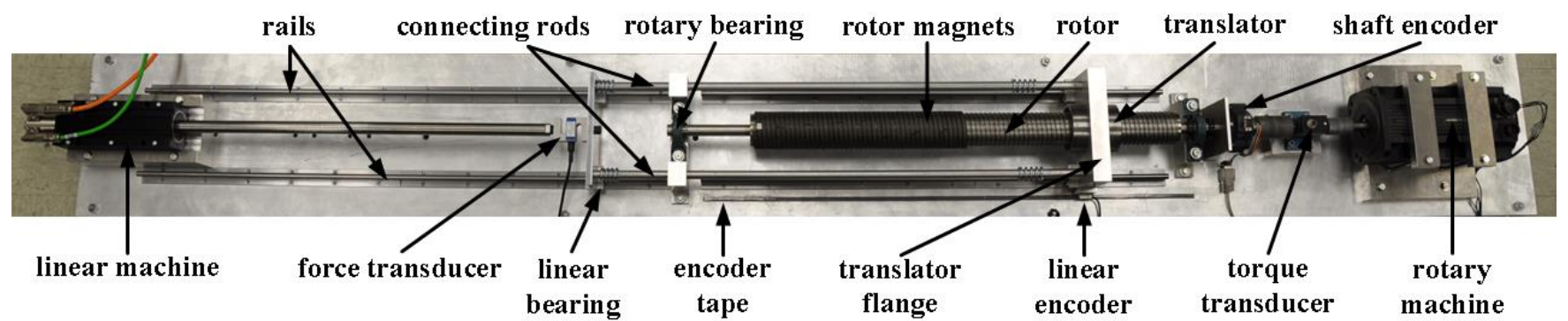

Fig. 3. Experimental TROMAG set-up assembly



Fig. 4. Zoomed in view of the TROMAG of Fig. 3

significantly save on weight and cost of the required material (ferromagnetic iron, copper, and magnet) compared to a direct drive linear PM machine that is designed for the same force and speed. It is shown in [18] that with typical magnet material and dimensions, shear stress of a TROMAG can reach almost 10 times that of a conventional PM linear machine. Intuitively, such superiority should hold a MITROMAG significantly lighter and compacter than a linear machine even after adding the cost and weight associated with the rotary machine that needs to be added to the TROMAG, given that the rotary machine operates at high speed and low torque. The goal of this paper is to quantify this advantage of MITROMAG over a PM LTM for different force ratings of design, as well as investigate the contribution of each of the two main parts of a MITROMAG to its overall weight and cost. In order to compare the two technologies, the approach taken here is to optimally design a MITROMAG for a constant force and speed and compare it, in terms of weight, volume, and cost of the material and electricity, with a linear machine that is optimally designed for the same specifications. The optimization problem framed for each topology has identical set of objectives, constraints and materials employed, thus making a fair comparison between the two. Multi-objective optimization to achieve lighter and less costly designs (which, in this paper, are referred to as "Pareto Optimal" designs) is performed by using GOSET 2.4, a population-based genetic algorithm (GA) toolbox [19]. Part III explains the design constraints, design constants, design variables, and the design procedure for the MITROMAG. The same is presented for the benchmark linear machine in part IV. The results of design optimization are demonstrated and discussed in part $\mathrm{V}$.

\section{OPTIMAL DESIGN OF A MITROMAG}

A MITROMAG consists of a TROMAG and a rotary machine that is coupled to the shaft of the rotor of the TROMAG. Due to this, the two components do not impose any geometric constraint on one another. However, the choice of gear ratio for the TROMAG determines the torque and rotational speed for which the rotary machine has to be designed. In general, optimal design of the MITROMAG entails simultaneous design of both the TROMAG and the rotary machine part.

\section{A. Design considerations}

\section{1) Choice of pole pitch}

The TROMAG is designed to meet the given force and speed, which can be achieved by the right combination of pole pitch, $\tau_{P}$, magnet height, $h_{M}$, magnet coverage, $\alpha$, rotor radius, and active length. According to (1), choosing a narrower thread (shorter pole pitch) results in a larger gear ratio and therefore lower torque and higher speed for the rotary machine, which means a higher power density design can be achieved for the rotary machine. However, a large rotational speed may cause rotor vibrations due to long stroke (and hence shaft) if the TROMAG is not perfectly concentric [20]. Moreover, considering the low stiffness of the TROMAG [16], a large rotational speed may also cause difficulties in controlling the system, especially given that the direction of rotation of rotor has to be reversed every time the translator reaches the end of its course of motion.

In addition, as shown in [18] a narrow thread can result in a poor shear stress for the TROMAG. Especially, as the air gap is increased for the larger systems there is a need for a longer pole pitch to maintain the shear stress at its optimum. Moreover, a narrower thread means that a higher number of magnet blocks have to be mounted, which leads to an increase in manufacturing complexity and cost. The consequence of a longer pole pitch is a lower gear ratio and larger torque demand on the rotary machine side of the MITROMAG.

\section{2) Dynamic behavior}

Another issue that mandates the simultaneous design of both parts is the dynamic performance, which is applicationspecific. The TROMAG effective gear ratio "seen" by the rotary machine can be different from the rated gear ratio given by (1). For example, it is shown in [21] that in an application like ocean wave energy the rotor moment of inertia would significantly affect the effective gear ratio when the wave energy conversion system is under the reactive control strategy. Such factors have to be considered when designing for a specific application.

\section{3) Overload capability}

An electric machine may be designed such that it can temporarily deliver more than its rated power upon injecting 
higher current. On the other hand, a TROMAG force cannot exceed the pull-out value which is determined by its magnetic design and is not controllable. To enable a fair comparison, for each case the TROMAG is designed for a pull out force that is 25\% larger than the rated force for which the LTM is designed. This assures that the TROMAG can operate at forces up to $25 \%$ higher than its rated value without slipping.

\section{4) Choice of rotary machine}

The best choice for rotary machine configuration, overall, depends on the application and optimization objectives. In this paper, a V-shaped interior permanent magnet machine (IPM) is chosen for the rotary machine part of the MITROMAG in order to achieve good torque density and efficiency at rated operating point. It has to be noticed however that depending on the specific application for which the MITROMAG is designed, surface-mount configuration or buried PM rotor configurations other than $\mathrm{V}$-shaped such as trough shaped or $\mathrm{PM}$-assisted synchronous reluctance may be superior to the Vshaped IPM.

In the following, design constraints, variables, and constants are given as well as a general design procedure for the MITROMAG.

\section{B. Design constraints, constants, and variables of a MITROMAG}

Design of the MITROMAG is performed for a given rated force and speed as the constraints. The speed is set at $1 \mathrm{~m} / \mathrm{s}$ for all designs. Several levels of pull-out force are considered from $1.25 \mathrm{kN}$ to $125 \mathrm{kN}$ (each $25 \%$ above the rated force of the corresponding LTM), which are corresponding to $1 \mathrm{~kW}$ to $100 \mathrm{~kW}$ power. Moreover, the winding maximum temperature is restricted to $180{ }^{\circ} \mathrm{C}$.

In this study, for the sake of a general design, designs are performed for constant speed of $1 \mathrm{~m} / \mathrm{s}$, and several values of constant force. It has also been decided to set the rotor speed at $3000 \mathrm{rpm}$. This way, the gear ratio of the TROMAG will be fixed at $100 \pi$ for all cases, and designs of TROMAG and rotary machine become mutually exclusive. Therefore, the TROMAG and rotary machine is designed separately, thus reducing the complexity of the optimization problem.

According to (1), a lower $P$ results in a larger gear ratio; hence, only 2-pole TROMAGs are considered here. Consequently, to achieve a gear ratio of $100 \pi$, in each case a 2-pole TROMAG with $10 \mathrm{~mm}$ pole pitch has to be optimally designed for the given force. Design variables for the TROMAG are then the magnet thickness $h_{M}$, magnet coverage (ratio of magnet width to pole pitch) $\alpha$, and rotor radius, some of which are illustrated in Fig. 1.

A 2D view of one pole of a V-shape IPM, along with its geometrical design variables, is shown in Fig. 5. For the IPM, the selected design variables are the slot-pole combination, $\left(N_{S}, N_{P}\right)$, magnet thickness, $h_{M}$, magnet angle, $\alpha_{V}$, rotor inner radius, $R_{r i}$, rotor outer radius, $R_{r o}$, split ratio (ratio of stator outer radius to the rotor outer radius), $S R$, stator core thickness, $d_{c s}$, tooth width $W_{t}$, slot opening $b_{0}$, slot tip height, $H_{s o}$, slot wedge height, $H_{s l}$, and the conductor current density,

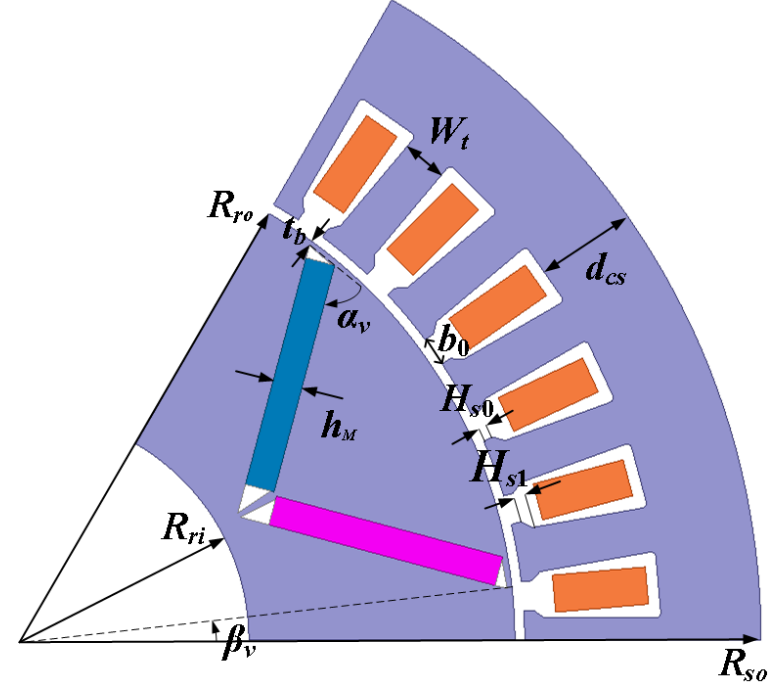

Fig. 5. One pole of the V-shaped rotary IPM and its geometrical design variables

$J$. Rotor length is assumed to equal the stator stack length. Bridge width $t_{b}$ is set at a constant value for all designs of a power level. The bridge thicknesses are chosen to be $0.5 \mathrm{~mm}$ for $1 \mathrm{~kW}, 1 \mathrm{~mm}$ for $10 \mathrm{~kW}$ and $2.5 \mathrm{~mm}$ for $100 \mathrm{~kW}$ designs based on the maximum chosen rotor outer diameter in order to maintain the structural integrity of the bridges at operating speed while considering a factor of safety. In addition, to avoid high switching frequencies, the maximum supply frequency is limited to $300 \mathrm{~Hz}$. With $3000 \mathrm{rpm}$ as the top speed, the maximum number of poles of the IPM is then restricted to 12 . The values considered for the "slot per pole per phase" are 1, $1.5,2$, and 3 .

In all designs, the air gap length for both the IPM and TROMAG is set at $1 \mathrm{~mm}$. Moreover, M19 laminations with $0.5 \mathrm{~mm}$ thickness and a stack factor of $95 \%$ are used for the IPM. Ferromagnetic iron such as 1020 steel can be employed for the TROMAG. NdFeB magnets with $B_{r}=1.1 \mathrm{~T}$ and $\mu_{r}=$ 1.05 are considered for both machines and the TROMAG. The ambient temperature, $T_{a m b}$ is set at $40{ }^{\circ} \mathrm{C}$. It is decided to account for the efficiency by adding the cost of electricity over a 5-year time period [22]. This cost represents the energy lost to losses if the system was used as a motor, or the energy that would not be harvested if the system was used as a generator. Electricity price is set at a constant value of $0.05 \$ / \mathrm{kWh}$. The cost of lamination steel, copper, and magnet is assumed to be 3,8 , and $90 \$ / \mathrm{kg}$, respectively.

\section{Design procedure of a MITROMAG}

\section{1) Design of the TROMAG}

Aspects of magnetic design of a TROMAG are discussed in detail in [18]. Main conclusions of that paper are summarized below:

- Magnets of rotor and translator, assuming that they are of the same material, have to be of the same thickness; otherwise the thinner magnets may get demagnetized.

- Assuming unity coverage for magnets, that is, if the magnets fully cover the pole pitch, for a given air gap length and 
magnet thickness there is an optimum pole pitch that maximizes the shear stress. For example, with $1 \mathrm{~mm}$ air gap and $5 \mathrm{~mm}$ thick $\mathrm{NdFeB}$ magnets that have $B_{r}=1.1$ and $\mu_{0}=1.05$, the optimum pole pitch is $10 \mathrm{~mm}$ and results in shear stress of $230 \mathrm{kN} / \mathrm{m}^{2}$. For practical values of magnet thickness and air gap length, the optimum pole pitch for maximizing the shear stress is usually about $10 \mathrm{~mm}$. That is why this value is chosen for all TROMAGs here.

- As the magnet thickness increases, the shear stress increases as well. However, the rate of increase plummets as thicker magnets are used.

- As the air gap length increases the shear stress decreases. To maintain a constant shear stress despite the increase of air gap length, both the magnet thickness and pole pitch have to be increased proportionally.

- For a given pole pitch, magnet thickness, and air gap length there is an optimum magnet coverage that maximizes the force per magnet volume. For example, with $10 \mathrm{~mm}$ pole pitch the maximum force per magnet volume turns out to be $40 \mathrm{MN} / \mathrm{m}^{3}$ and is achieved in the case of $2 \mathrm{~mm}$ thick magnets with $65 \%$ coverage. As the rare earth magnets are the main contributor to the cost of a TROMAG, this is an important aspect of optimization.

- If the stroke is not considered the individual values of air gap radius and length of the active air gap area will not affect the cost and weight; however, when the stroke is accounted for, longer parts with smaller radius are more preferable in terms of material consumption especially if the stroke is long compared to the active length of the TROMAG.

Restrictions on outer radius and total length are imposed by the space restrictions of a certain application. Even without any space restrictions, very long rotors with small radius should be avoided as they are more prone to rotor deflection and consequently unbalanced radial forces [13]. In the studied TROMAG it is assumed that the outer part is the translator and it is longer than the rotor by the amount of stroke. The rotor length to radius ratio is also set at 12 . In each design case, magnet thickness and coverage are varied and the total weight and cost of the material are obtained. An accurate analytical model is used for calculating the TROMAG axial force [14]. The model is derived from field equations and has shown very good agreement with 2D FEA.

It is shown in [15] that in an ideal TROMAG as long as the rotor and translator are moving in synchronism, which is the case in steady state operation, the relative position of rotor magnets and translator magnets remains constant. Therefore, the losses in magnets and iron cores are expected to be insignificant. The main losses of a TROMAG are then attributed to the bearings. The $17 \mathrm{kN}$ lab prototype presented in [13] has exhibited an efficiency of over $90 \%$ at most operating points. Higher efficiencies are expected as the technology matures. In this study, efficiency of the TROMAG is assumed to be independent from the magnetic design, and is set at $95 \%, 92 \%, 90 \%$, and $80 \%$ for force levels of $125 \mathrm{kN}$,
$62.5 \mathrm{kN}, 12.5 \mathrm{kN}$, and $1.25 \mathrm{kN}$ respectively.

\section{2) Design of the IPM}

In each case, the IPM rated torque is obtained from (1) by knowing the gear ratio (fixed at $100 \pi$ ) and the rated force for which the MITROMAG is designed. Notice that $25 \%$ margin is not considered for the rotary machine because, similar to the LTM, it can be designed to be capable of delivering higher power for short periods of time. The IPM speed is also set at $3000 \mathrm{rpm}$ for all designs. Design optimization of the IPM is performed by using multi-objective GA. Each "individual" design generated by the GA is evaluated by employing twodimensional (2D) magnetic FEA combined with thermal calculations based on an approximate thermal circuit to determine the operating temperature. Material properties are updated with temperature to recalculate losses and this process is performed iteratively until operating temperature converges. As the first step, the slot geometry is created and populated with wires accounting for the wire enamel, varnish, and slot lining [23]. The inter-strand distance is calculated based on practical data from manufactured machines. The conductor fill factor can then be obtained by dividing the area occupied by copper to the whole slot area. In addition, once the slot is populated, the heat generated in the slot (slot copper losses) is calculated for an arbitrary current density. Assuming a unity stack length, a thermal FEA is then performed to obtain the resultant temperature distribution in the slot. Upon dividing the highest temperature in the slot, $T_{s p o t}$ by the slot copper loss, the thermal resistivity from the hot spot to the core $\rho_{\text {th- spot }}$ is obtained in ${ }^{\circ} \mathrm{C} . \mathrm{m} / \mathrm{W}$. Average temperature of the slot is also calculated and divided by the slot heat to obtain the average thermal resistance from the winding to the core, $\rho_{t h-a v g}$. while the latter parameter is later used for calculating the average temperature of the slot to find the average copper resistivity, the former parameter is used for calculating the winding hot spot to ensure the insulation thermal limit is respected.

The next step is to create the IPM geometry for performing the magnetic FEA. In order to save on computations time, periodic or anti-periodic boundary conditions are imposed so analyzing a fraction pole of the machine suffices. By knowing the current density, as an attribute of each individual, and conductor fill from the previous step the phase current can be calculated. Since the selected rotor configuration is salient, the maximum torque position depends on the $\mathrm{d}$-axis and q-axis inductances, $L_{d}$ and $L_{q}$, as well as the PM flux linkage, $\lambda_{M}$. Therefore, a magneto-static FEA is run to obtain $L_{d}, L_{q}$ and $\lambda_{M}$ at the given phase current. Moreover, the phase current is injected in the negative d-axis direction and the flux density distribution in the PM is obtained to ensure demagnetization will not occur. To obtain the average torque, accounting for the torque ripple, the rotor is rotated by 180 electrical degrees over 24 equal steps. At each step a static 2D magnetic FEA is performed and the torque per unit of stack length is calculated. Iron losses, $P_{F e}$, including hysteresis, classic eddy, and excess eddy losses are also calculated at each step by using the "CAL2" iron loss model [24]. 
The required stack length, $L_{\text {stack }}$ to yield the desired torque can then be calculated. The total copper loss, $P_{c u}$ is calculated accounting for the end winding length. Eddy current loss in $\mathrm{PMs}$ is considered negligible assuming that the PMs are segmented [25]. Afterwards, the winding hot spot temperature is checked against the maximum temperature constraint. To calculate $T_{s p o t}$, first the core temperature, $T_{\text {core }}$ is calculated from (2).

$$
T_{\text {core }}=T_{\text {amb }}+R_{\text {th, core }} \times\left(P_{C u}+P_{F e}\right)
$$

In (2), $R_{\text {th_core }}$ is the thermal resistance between the stator housing and the ambient, and is given in (3).

$$
R_{\text {th, core }}=1 /(h A)
$$

In (3), $A$ is the housing area and $h$ is the heat transfer coefficient in $\mathrm{W} / \mathrm{m}^{2} .{ }^{\circ} \mathrm{C}$. The coefficient $h$ is calculated through an empirical thermal model, assuming a TEFC structure [26]. The fluid velocity at the surface of housing, required for calculation of $h$, is roughly approximated to be $10,15,20$, and $30 \mathrm{~m} / \mathrm{s}$ for $1,10,50$, and $100 \mathrm{~kW}$ machines rotating at 3000 $\mathrm{rpm}$, based on the experimental data available for induction motors. Also, the outer area of the stator core is roughly taken as the housing area.

Once the core temperature is known, the winding hot spot temperature can be determined from (4) to ensure it is below the maximum permissible temperature for the insulation. Otherwise, the individual design is discarded.

$$
T_{\text {spot }}=T_{\text {core }}+\left(\rho_{\text {th, spot }} / L_{\text {stack }}\right) \times P_{C u}
$$

Eventually, the cost of the active material, $C_{m}$ and their weight, $M_{t o t}$ are calculated as well as the cost of losses, $C_{e}$. The GA objective is to minimize both quantities.

\section{OPTIMAL DESIGN OF THE LTM}

Due to their high force density, high efficiency, and dynamic characteristics, linear PM machines are proposed as a strong contender for a variety of applications from servo drives and aerospace actuators to transportation and wave energy conversion systems. In [27], a flat double-sided linear PM machine with surface mount magnets is manufactured for a wave energy converter. Here, a PM linear machine with tubular structure, similar to [28], is considered as the benchmark because of its similarity to the TROMAG structure. In this structure there are no end windings, which is an advantage over a flat structure.

The approach taken here for optimal design of an LTM, similar to the rotary IPM, is the use of thermal and magnetic FEA for evaluation of each individual design generated by the GA. To enable a fair comparison with the rotary machine, a similar thermal analysis is performed assuming the same air velocities over the stator core of the LTM as those of the rotary IPM. It will be observed however, that incorporating the efficiency in the cost calculation results in the current density being mainly capped by the efficiency-tied cost of the system not by the temperature limit.

\section{A. Design constraints, constants, and variables of the PM LTM}

Design constraints of the LTM are the same as those of the MITROMAG: the speed is set at $1 \mathrm{~m} / \mathrm{s}$ for all designs, and power levels from 1 to $100 \mathrm{~kW}$ are considered. The winding maximum temperature is limited to $180{ }^{\circ} \mathrm{C}$. No restriction is posed on the radius and length of the machine.

An LTM is shown in Fig. 6 along with its geometrical design variables. Given the tubular structure of the machine, only full pitch windings with one slot per pole per phase are considered [29]. The selected design variables are the rotor outer radius $R_{m}$, pole pitch, $\tau_{P}$, magnet thickness $h_{M}$, magnet coverage (ratio of magnet width to pole pitch $w / \tau_{P}$ ) $\alpha$, tooth width $W_{t}$, winding height $h_{W}$, slot opening $b_{0}$, slot tip height $H_{s 0}$, slot wedge height $H_{s l}$, translator core thickness, $d_{c t}$, stator core thickness, $d_{c s}$, and the conductor current density $J$.

Lamination material and thickness, stack factor, magnet material, cost of material and electricity, air gap length, and the ambient temperature are assumed equal to the corresponding values for the rotary IPM.

\section{B. Design procedure of a PM LTM}

Similar to the rotary IPM, the first step of evaluating each individual is to create its slot geometry and populate the slots in order to obtain the conductor fill factor. Thermal FEA is

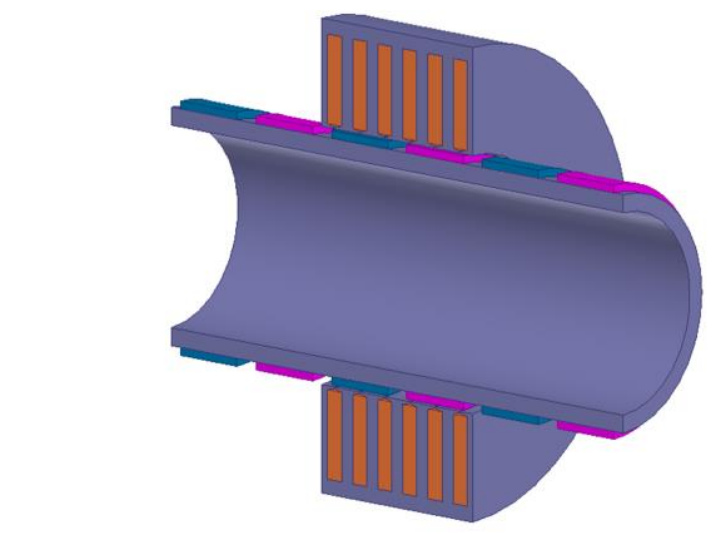

(a)

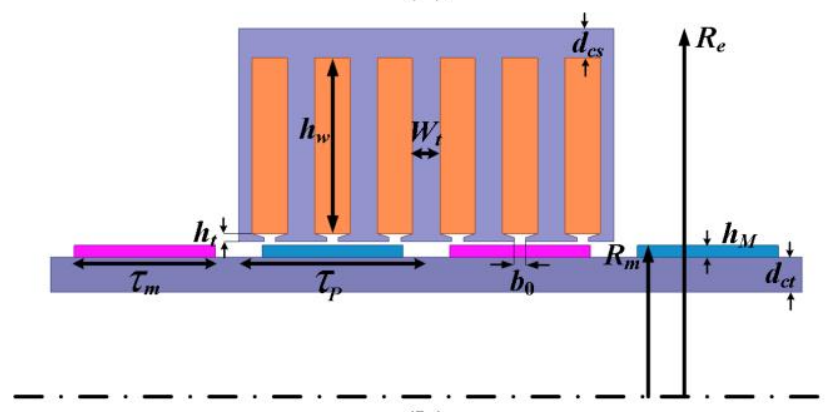

(b)

Fig. 6. A PM LTM and its geometrical design variables; (a) cut-away view, and (b) $2 \mathrm{D}$ view 
then run and the thermal resistivity between slot and core is calculated. By knowing the current density of the individual and its conductor fill factor, the copper losses of one pole is calculated. Low speed of the motion implies negligible iron losses; hence, only the copper losses are accounted for in calculating the winding hot spot temperature and ensuring that the insulation thermal limit is respected.

In the next step, geometry of one pole of the machine is created in axis symmetric magnetic FEA and phase currents and anti-periodic boundary conditions are applied. Afterwards, the translator is moved by one slot pitch and the average force generate by one pole, $F_{\text {pole }}$ is calculated. Moreover, the flux density vector is extracted for iron loss calculations.

By knowing $F_{\text {pole }}$, the total number of poles required to achieve the desired force can be obtained. Eventually, the total weight and cost of iron, copper, and magnet are calculated. Losses are incorporated in total cost calculation considering a 5 -year time period.

\section{RESULTS}

Fig. 7 shows contour plots of force per cost and weight of the TROMAG with $10 \mathrm{~mm}$ pole pitch and $1 \mathrm{~mm}$ air gap versus magnet thickness and magnet coverage, assuming zero stroke. The last assumption makes the plots independent from the force for which the design is performed. These plots illustrate the ranges of magnet thickness and coverage for optimum material cost and weight. Core thickness is set at $10 \mathrm{~mm}$ for both the rotor and translator to provide mechanical rigidity.

A maximum of $47 \mathrm{~N} / \$$ is achieved for the force per cost with $2.2 \mathrm{~mm}$ thick magnets and $70 \%$ coverage. The force per weight for the given magnet thickness and coverage works out to $0.7 \mathrm{kN} / \mathrm{kg}$.

On the other hand, maximum force per weight of $1 \mathrm{kN} / \mathrm{kg}$ occurs when magnets turn out to be $4.9 \mathrm{~mm}$ thick and cover $90 \%$ of the pitch. Such a design would result in force per cost of $34 \mathrm{~N} / \$$. It must be noticed, however, that with the assumed efficiencies, the cost of electricity associated with losses dominates the material cost. For the case of $125 \mathrm{kN}$ TROMAG, assuming that it operates at $100 \mathrm{~kW}, 5 \%$ loss translates to about $\$ 11000$ over 5 years whereas the material cost assuming $34 \mathrm{~N} / \$$ would be only $\$ 3700$. This means that the two objectives are not strongly conflicting and can be concurrently optimized. Therefore, under the made assumptions, designs that minimize the weight can be picked without significantly compromising the overall cost.

When accounting for the stroke, the individual values of radius and length affect the material weight and cost, and the optimum design would depend on the desired pull-out force as well. For $125 \mathrm{kN}$ pull out force, stroke of $1 \mathrm{~m}$, and rotor length to radius ratio of 12 , the optimum values of magnet thickness, magnet coverage and active length of the translator to minimize the cost are $1.9 \mathrm{~mm}, 70 \%$, and $1.5 \mathrm{~m}$, respectively. This design results in force per cost of $35 \mathrm{~N} / \$$ and force per weight of $0.44 \mathrm{kN} / \mathrm{kg}$. To minimize the weight, the optimum values are $4.5 \mathrm{~mm}, 90 \%$, and $1.1 \mathrm{~m}$, which yield force per cost of $24 \mathrm{~N} / \$$ and force per weight of $0.65 \mathrm{kN} / \mathrm{kg}$. Compared to



(a)

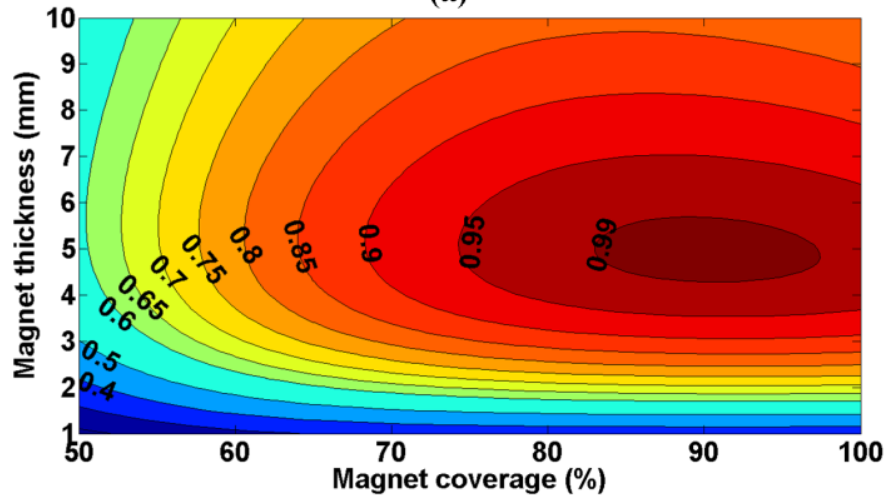

(b)

Fig. 7. Contour plots of variations of force per cost and force per weight of a TROMAG with zero stroke vs magnet thickness and coverage; (a) force per cost $(\mathrm{N} / \$)$, (b) force per weight $(\mathrm{kN} / \mathrm{kg})$.

the case of zero stroke, the optimum values of magnet thickness and coverage have slightly changed and the increase in weight and cost is noticeable. In the presented case, the stroke is not very different from the optimum values for the active length. As the stroke increases, the cost and weight associated with it would gradually overshadow those of the active part. Design details of the $125 \mathrm{kN}$ TROMAG above for the cases of optimum cost and optimum weight are summarized in Table I. Subscript " $a$ " denotes the association of a quantity to active material; that is, material which is not used to provide the stroke. $L_{a}, M_{a}$, and $C_{a}$ denote the length, mass, and cost of the magnetically engaged parts while $M_{\text {stroke }}$ and $C_{\text {stroke }}$ denote the weight and cost associated with the material added to provide the stroke. $C_{e}$ signifies the cost pertinent to losses, and $C_{t o t}$ represents the total cost. To calculate the volume, $V_{t o t}$, largest length and radius of the design are employed.

Optimal design of rotary IPM for $100 /(100 \pi) \mathrm{kN} . \mathrm{m}$ is performed using a two-objective GA. In order for both objectives to converge while achieving a reasonable data set, a population size of 200 over 20 generations is used. The Pareto optimal front is shown in Fig. 8. The conflict of cost and weight as optimization objectives is clearly observed.

Three designs are chosen from the Pareto optimal front: a design with low cost, a design with low weight, and a design which exhibits a compromise between the two objectives. Main details of the three designs are presented in Table II along with their corresponding weight, cost, and efficiency. $C_{m}$ 
denotes cost of the active material. For IPM \#2, a populated slot and its temperature distribution for an arbitrary current density of $12 \mathrm{~A} / \mathrm{mm}^{2}$, obtained from thermal FEA, is shown in Fig. 9 as well as the design geometry and mesh in magnetic FEA.

Weight and cost of the three IPM designs presented in Table II are added to those of a $125 \mathrm{kN}$ TROMAG with $1 \mathrm{~m}$ stroke to yield the total MITROMAG cost and weight. For the TROMAG, design with optimum weight is picked. Results, graphically presented in Fig. 10, are given in Table III. It is observed that at this force level, while the rotary machine has a weight comparable to that of the TROMAG, its contribution to the overall cost of a MITROMAG is less significant. The reason lies within the extensive use of costly rare-earth magnet material by the TROMAG, as opposed to the dominance of iron and copper in the IPM design. Also, the magnetically engaged material dominates the material used for the stroke. Moreover, for both the TROMAG and IPM, loss-related cost is noticeably greater than the material cost.

Similarly, an LTM is optimally designed for $100 \mathrm{kN}$ and 1 $\mathrm{m}$ stroke. Minimum core thickness for both stator and translator is set at $10 \mathrm{~mm}$. Table IV presents details of three designs picked from the Pareto optimal front, and Fig. 11 shows LTM\#2 in magnetic FEA. For better clarification,

TABLE I

DESIGN DETAILS OF A 125 KN TROMAG WITH 1 MM AIR GAP, 1 M STROKE, AND LENGTH TO RADIUS RATIO OF 12

\begin{tabular}{c|c|c}
\hline & $\begin{array}{c}\text { Minimum } \\
\text { initial cost }\end{array}$ & $\begin{array}{c}\text { Minimum } \\
\text { weight }\end{array}$ \\
\hline$h_{M}(\mathrm{~mm})$ & 1.9 & 4.5 \\
\hline$\alpha$ & 0.7 & 0.9 \\
\hline$R_{m}(\mathrm{~mm})$ & 126 & 88 \\
\hline$L_{a}(\mathrm{~m})$ & 1.5 & 1.1 \\
\hline$F / C(\mathrm{~N} / \$)$ & 35 & 24 \\
\hline$F / W(\mathrm{~N} / \mathrm{kg})$ & 441 & 650 \\
\hline$V_{\text {tot }}(\mathrm{Lit})$ & 151 & 69 \\
\hline$M_{a}(\mathrm{~kg})$ & 210 & 127 \\
\hline$M_{\text {stroke }}(\mathrm{kg})$ & 73 & 66 \\
\hline$M_{\text {tot }}(\mathrm{kg})$ & 283 & 192 \\
\hline$C_{a}(\mathrm{k} \$)$ & 2.7 & 3.5 \\
\hline$C_{\text {stroke }}(\mathrm{k} \$)$ & 0.9 & 1.7 \\
\hline$C_{e}(\mathrm{k} \$)$ & 10.9 & 10.9 \\
\hline$C_{\text {tot }}(\mathrm{k} \$)$ & 14.5 & 16.1 \\
\hline
\end{tabular}

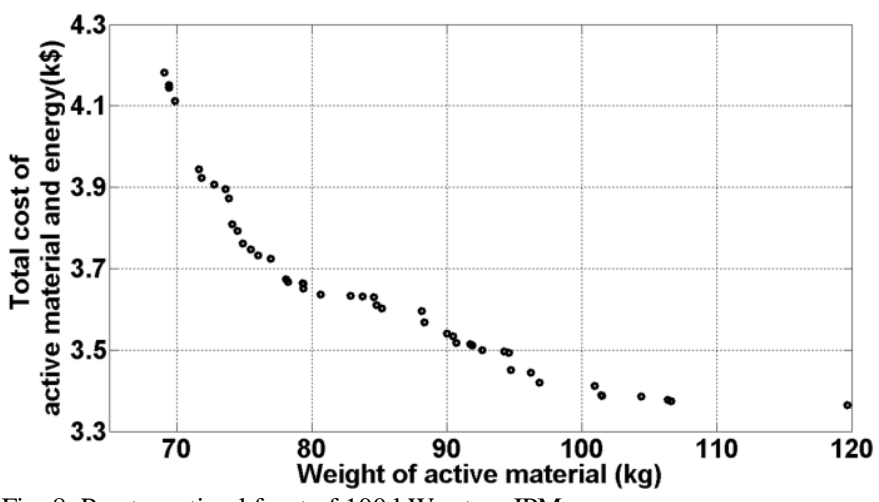

Fig. 8. Pareto-optimal front of $100 \mathrm{~kW}$ rotary IPM
TABLE II

DESIGN DETAILS OF THREE OPTIMALLY DESIGNED 100 KW IPMS FROM THE PARETO OPTIMAL FRONT

\begin{tabular}{c|c|c|c}
\hline IPM Design \# & 1 & 2 & 3 \\
\hline$N_{S}, N_{P}$ & 36,8 & 54,12 & 72,12 \\
\hline$R_{r i}(\mathrm{~mm})$ & 48.3 & 61.7 & 44.0 \\
\hline$R_{r o}(\mathrm{~mm})$ & 170 & 175.1 & 151.8 \\
\hline$h_{M}(\mathrm{~mm})$ & 6.1 & 6.1 & 6.3 \\
\hline SR & 1.4 & 1.3 & 1.4 \\
\hline$W_{t}(\mathrm{~mm})$ & 9.9 & 7.1 & 4.1 \\
\hline$d_{c s}(\mathrm{~mm})$ & 19.7 & 14.2 & 10.2 \\
\hline$b_{0}(\mathrm{~mm})$ & 7.2 & 7.2 & 4.9 \\
\hline$H_{s 0}(\mathrm{~mm})$ & 3.1 & 3.2 & 2.6 \\
\hline$H_{s l}(\mathrm{~mm})$ & 1.5 & 1.6 & 2.6 \\
\hline$\left.J(\mathrm{~A} / \mathrm{mm})^{2}\right)$ & 4.4 & 4.7 & 5.7 \\
\hline$K_{f}$ & 0.56 & 0.59 & 0.56 \\
\hline$e f f(\%)$ & 98.9 & 98.8 & 98.6 \\
\hline$V_{\text {tot }}(\mathrm{Lit})$ & 16.5 & 13.1 & 11.7 \\
\hline$M_{\text {tot }}(\mathrm{kg})$ & 105 & 79 & 70 \\
\hline$C_{m}(\mathrm{k} \$)$ & 1.1 & 1.0 & 1.0 \\
\hline$C_{e}(\mathrm{k} \$)$ & 2.3 & 2.7 & 3.1 \\
\hline$C_{\text {tot }}(\mathrm{k} \$)$ & 3.4 & 3.7 & 4.1 \\
\hline & & &
\end{tabular}

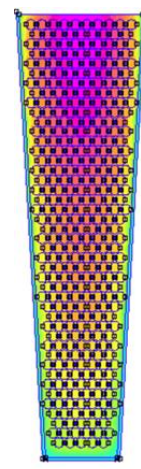

(a)

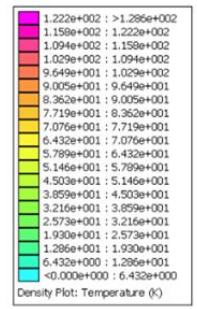

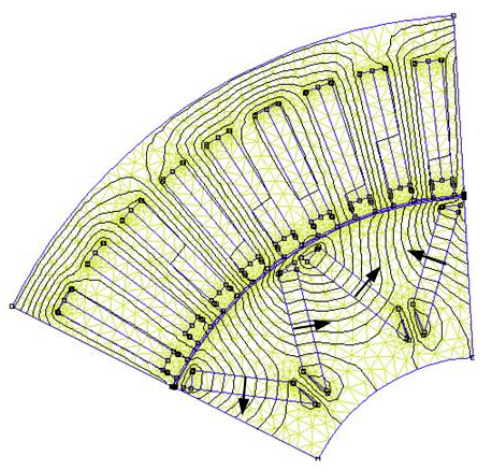

(b)
Fig. 9. Thermal and magnetic FEA of IPM design \#2; (a) a populated slot and its temperature distribution, (b) mesh and flux lines in magnetic FEA.

weights and costs of the three LTM designs are shown in Fig. 12. Clearly, less costly designs use lower current density to reduce the loss-related cost. Moreover, they tend to have larger radius, longer pole pitch, and larger volume. Lighter designs are longer and more compact, with higher current density and lower efficiency. The winding temperature approaches the maximum permissible value for lighter designs, but for cost effective designs it remains well below that value. It is also interesting to learn that, in contrast with the TROMAG, the cost and weight associated with the material required for the stroke is very small compared to those of active material. In addition to very large shear stress of the TROMAG compared to that of a PM LTM, this is due to the fact that length to radius ratio of the LTM is not restricted, and the Pareto optimal designs tend to have large lengths; several times the stroke. Comparing Tables III and IV clearly indicates the superiority of the MITROMAG over LTM. For example, in design \#1 the MITROMAG is an order of magnitude lighter and compacter than the corresponding LTM while its cost is 


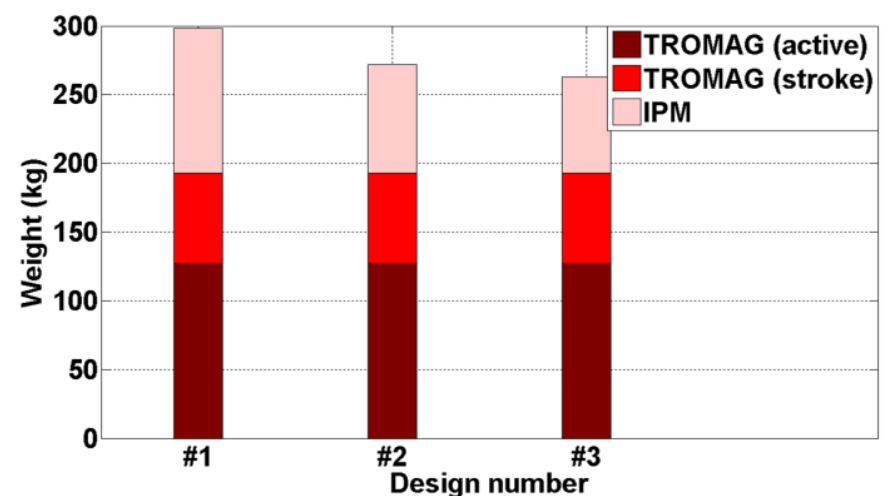

(a)

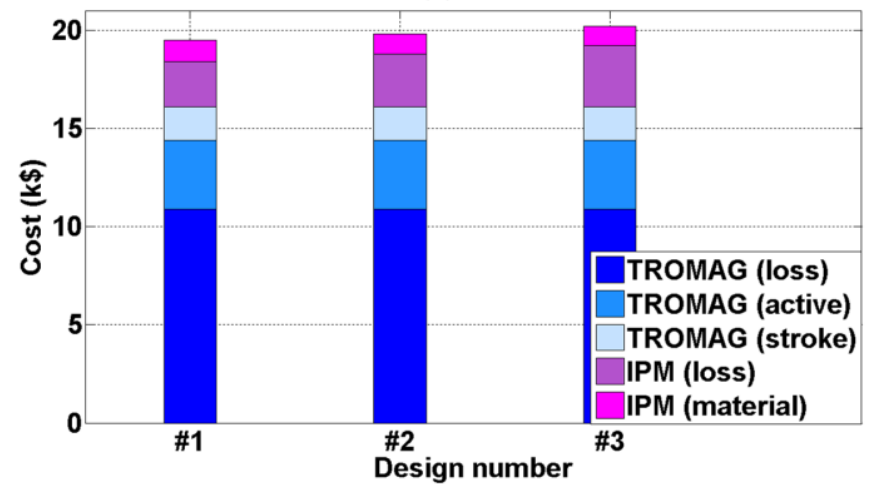

(b)

Fig. 10. Weights and costs of three designs of a $100 \mathrm{~kW}$ MITROMAG; (a) weight, and (b) cost of material and energy

TABLE III

VOLUME, WEIGHT, AND COST OF THREE $100 \mathrm{KW}$ MITROMAGS CORRESPONDING TO OPTIMUM IPMS OF TABLE II

\begin{tabular}{c|c|c|c}
\hline Design \# & $\# 1$ & $\# 2$ & $\# 3$ \\
\hline$V_{\text {tot }}(\mathrm{Lit})$ & 85.5 & 82.1 & 80.7 \\
\hline$M_{a}(\mathrm{~kg})$ & 231.5 & 206.2 & 197.1 \\
\hline$M_{\text {stroke }}(\mathrm{kg})$ & 66 & 66 & 66 \\
\hline$M_{\text {tot }}(\mathrm{kg})$ & 297.5 & 272.2 & 263.1 \\
\hline$C_{a}(\mathrm{k} \$)$ & 4.6 & 4.5 & 4.5 \\
\hline$C_{\text {stroke }}(\mathrm{k} \$)$ & 1.7 & 1.7 & 1.7 \\
\hline$C_{e}(\mathrm{k} \$)$ & 13.2 & 13.6 & 14.0 \\
\hline$C_{\text {tot }}(\mathrm{k} \$)$ & 19.5 & 19.8 & 20.2 \\
\hline \multicolumn{2}{|r|}{}
\end{tabular}

less than half of the LTM. Also notice that inactive material required for maintaining the air gap is not considered when comparing the weights of the two systems. For large direct drive systems the inactive material contributes to the most of the system total weight [30]. Since MITROMAG is much lighter and compacter, it is expected to need less inactive material compared to the LTM; thus its overall weight would be further reduced.

Designs are repeated for power levels of 50,10, and $1 \mathrm{~kW}$ for the same stroke and air gap length. Weight and cost of MITROMAG and LTM is compared in Fig. 13. As the force level decreases with the stroke length being constant, the MITROMAG significant margin of advantage over the LTM gradually shrinks. At $1.25 \mathrm{kN}$, for example, the stroke length of TROMAG turns out to be more than 10 times its magnetically engaged length. With the efficiency assumed for TROMAG at this force level, the MITROMAG cost approaches that of the LTM, although its weight and volume are still lower than those of the PM LTM.

So far, to exclude the influence of air gap length, this parameter has been kept constant for all designs. Choosing the right value for the air gap, especially for the two less-known systems, the PM LTM and the TROMAG, entails further research and manufacturing experience. Factors such as shaft material stiffness, manufacturing tolerances, possible eccentricities and resultant unbalanced magnetic pulls, and rotor speed can affect the required air gap length. To study the effect of air gap length, design of the $100 \mathrm{~kW}$ PM LTM has been repeated for two air gap length values of 2 and $3 \mathrm{~mm}$, and the Pareto-optimal fronts corresponding to different values of

TABLE IV

DESIGN DETAILS OF THREE OPTIMALLY DESIGNED 100 KW LTMS FROM THE PARETO OPTIMAL FRONT

\begin{tabular}{|c|c|c|c|}
\hline $\begin{array}{c}\text { PM LTM } \\
\text { Design\# }\end{array}$ & 1 & 2 & 3 \\
\hline$R_{m}(\mathrm{~mm})$ & 161 & 160 & 93.5 \\
\hline$\tau_{P}(\mathrm{~mm})$ & 48.6 & 37.3 & 30 \\
\hline$h_{M}(\mathrm{~mm})$ & 5.2 & 3.6 & 4.5 \\
\hline$\alpha$ & 0.84 & 0.68 & 0.74 \\
\hline$W_{t}(\mathrm{~mm})$ & 8.0 & 5.3 & 4.4 \\
\hline$h_{W}(\mathrm{~mm})$ & 77.4 & 32.0 & 35.9 \\
\hline$b_{0}(\mathrm{~mm})$ & 2.5 & 3.2 & 3.3 \\
\hline$H_{s 0}(\mathrm{~mm})$ & 0.6 & 0.8 & 0.6 \\
\hline$H_{s l}(\mathrm{~mm})$ & 2.0 & 2.1 & 0.8 \\
\hline$d_{c t}(\mathrm{~mm})$ & 13.1 & 10 & 10 \\
\hline$d_{c s}(\mathrm{~mm})$ & 10 & 10 & 10 \\
\hline$J\left(\mathrm{~A} / \mathrm{mm}^{2}\right)$ & 2.0 & 4.2 & 6.5 \\
\hline$K_{f}$ & 0.55 & 0.48 & 0.49 \\
\hline$F_{\text {pole }}(\mathrm{N})$ & 1404 & 796 & 685 \\
\hline eff $(\%)$ & 88.3 & 78.1 & 64.0 \\
\hline$V_{\text {tot }}$ (Lit) & 897 & 764 & 344 \\
\hline$M_{a}(\mathrm{~kg})$ & 2973 & 1862 & 1178 \\
\hline$M_{\text {stroke }}(\mathrm{kg})$ & 123 & 89 & 53 \\
\hline$M_{t o t}(\mathrm{~kg})$ & 3096 & 1951 & 1231 \\
\hline$C_{a}(\mathrm{k} \$)$ & 23.0 & 15.1 & 10.4 \\
\hline$C_{\text {stroke }}(\mathrm{k} \$)$ & 3.2 & 1.9 & 1.4 \\
\hline$C_{e}(\mathrm{k} \$)$ & 25.6 & 48.1 & 78.7 \\
\hline$C_{t o t}(\mathrm{k} \$)$ & 51.8 & 65.1 & 90.5 \\
\hline$T_{\text {spot }}\left({ }^{\circ} \mathrm{C}\right)$ & 66 & 91 & 167 \\
\hline
\end{tabular}

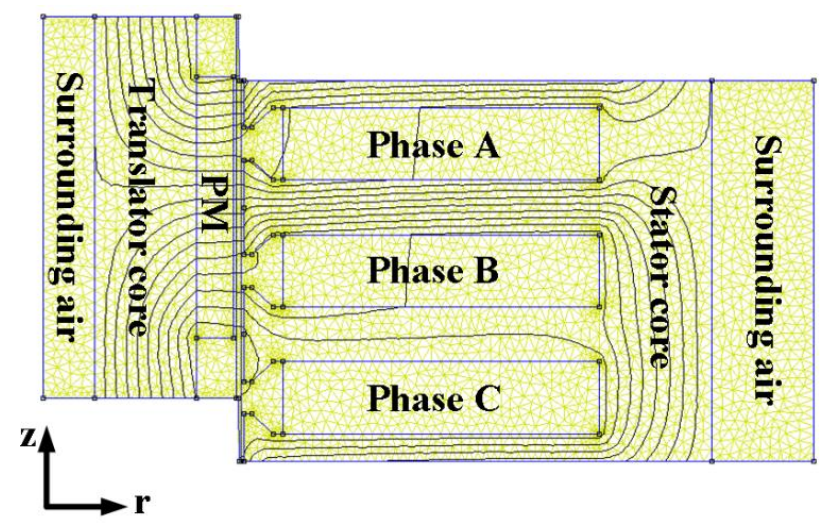

Fig. 11. Mesh and flux lines of LTM design \#2 in magnetic FEA 


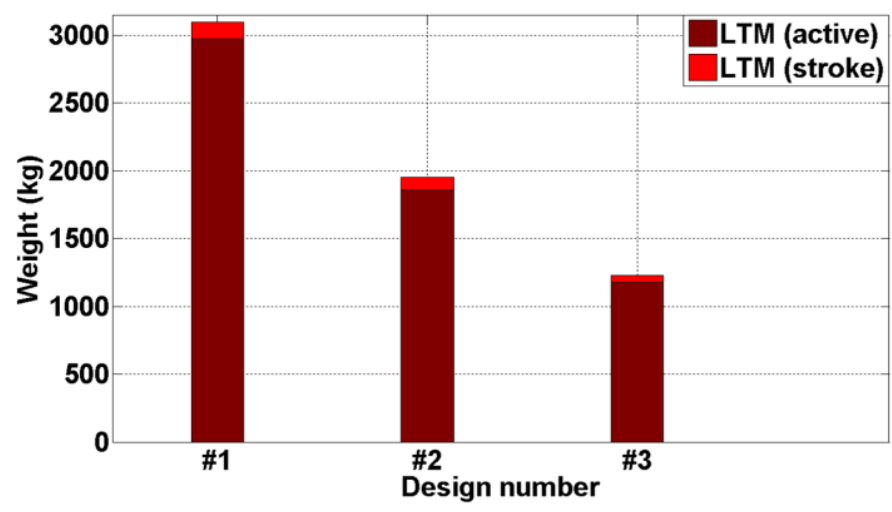

(a)

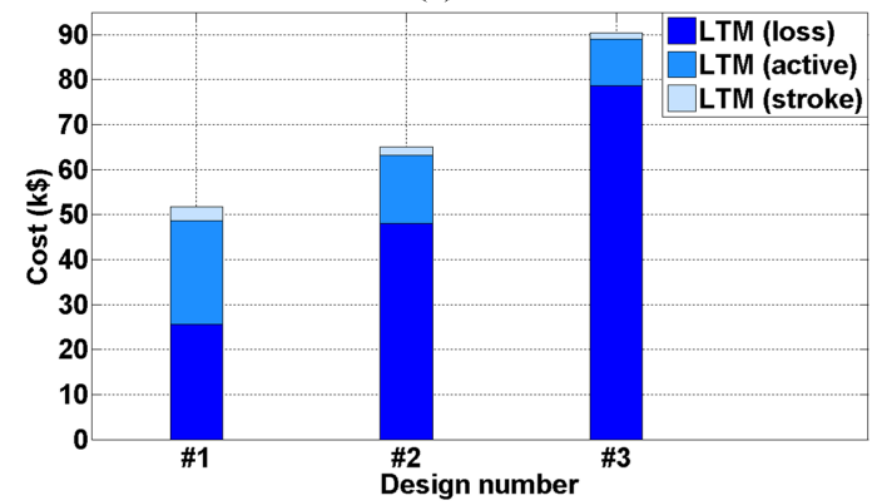

(b)

Fig. 12. Weights and costs of three designs of a $100 \mathrm{~kW} \mathrm{LTM;} \mathrm{(a)} \mathrm{weight,} \mathrm{and}$ (b) cost of material and energy.

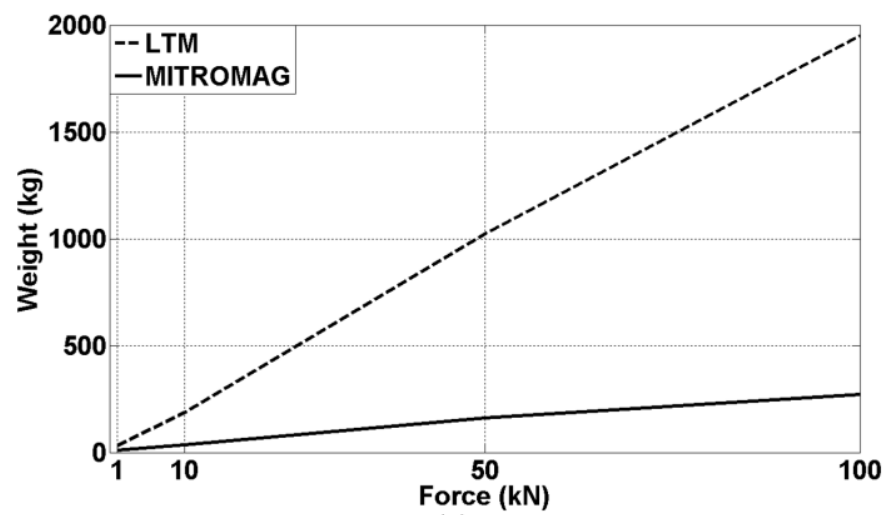

(a)

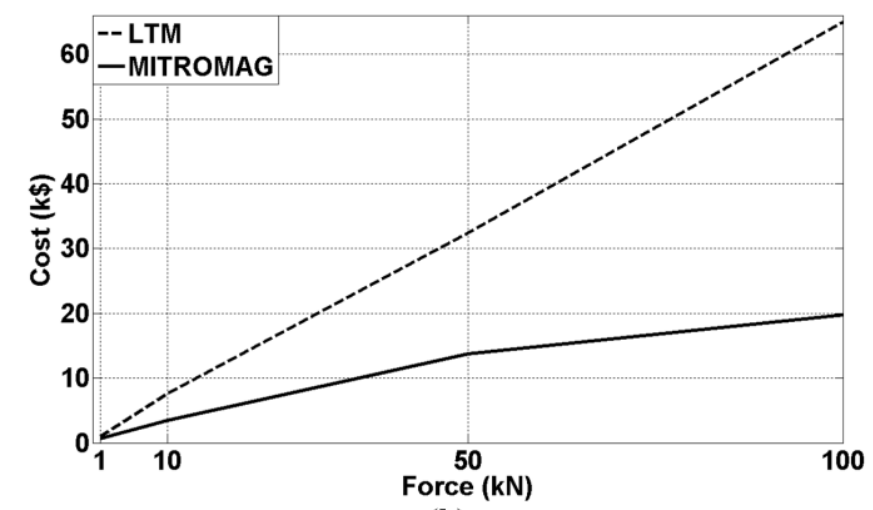

Fig. 13. Comparison of MITROMAG and PM LTM at four levels of force with similar speed and stroke; (a) weight, and (b) cost air gap are shown in Fig. 14. The effect of an increased air gap length on the total weight and cost is clearly observed. Fig. 15 presents the Pareto-optimal fronts corresponding to TROMAGs with different air gap lengths (other parameters are kept the same as designs presented above). To obtain these curves, the cost and weight associated with material are considered only. As an example, for the case of $100 \mathrm{~kW}$ power and $1 \mathrm{~m}$ stroke, a low-weight, high-cost design of MITROMAG is compared with a low-weight, high-cost design of LTM for air gap lengths of $1 \mathrm{~mm}$ and $3 \mathrm{~mm}$. A similar comparison is also made for high-weight, low-cost designs. The results are presented in Table V. For the studied case, the adverse influence of an increased air gap length on material consumption and cost is more on the MITROMAG than on the LTM, although the MITROMAG still maintains a great margin of advantage over the LTM.

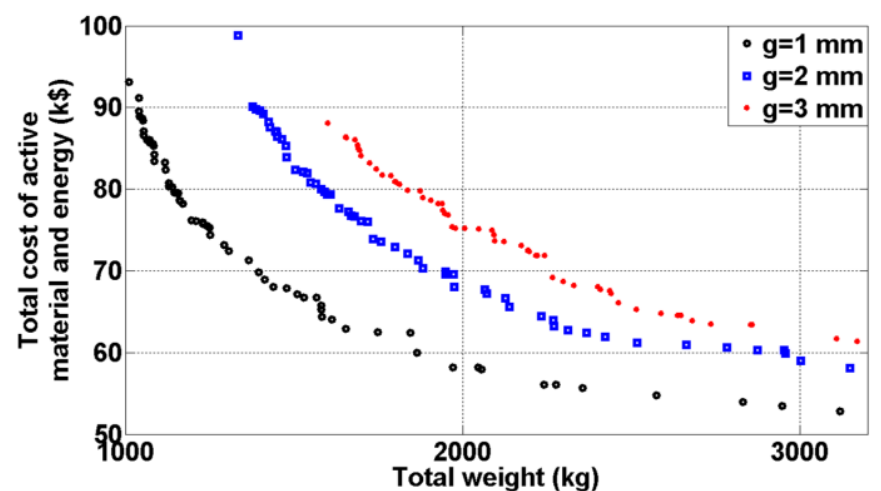

Fig. 14. Pareto-optimal fronts of $100 \mathrm{~kW}$ LTMs with different values of air gap length

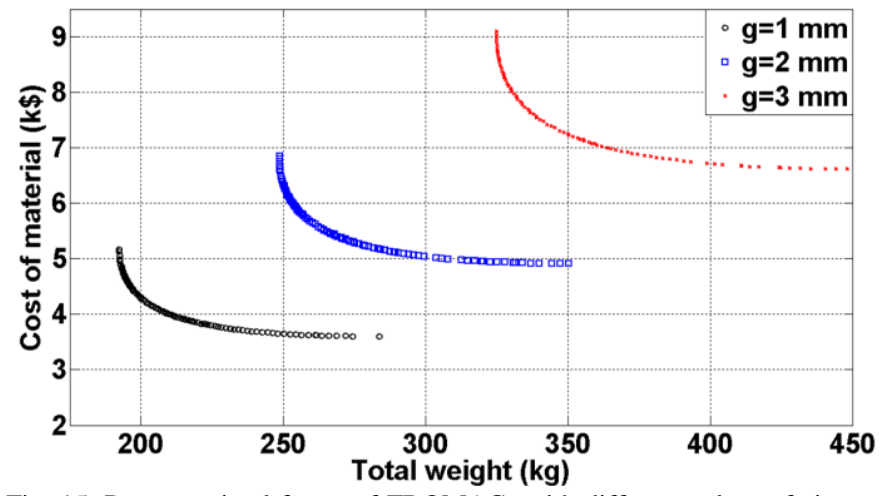

Fig. 15. Pareto-optimal fronts of TROMAGs with different values of air gap length

TABLE V

COMPARISON OF TOTAL WEIGHT AND TOTAL COST OF $100 \mathrm{KW}, 1$ M STROKE MITROMAG AND LTM FOR 1 MM AND 3 MM AIR GAP LENGTHS

\begin{tabular}{c|c|c|c|c}
\hline \multirow{2}{*}{} & \multicolumn{2}{|c|}{$\begin{array}{c}\text { A low-weight, high- } \\
\text { cost design }\end{array}$} & \multicolumn{2}{c}{$\begin{array}{c}\text { A high-weight, low- } \\
\text { cost design }\end{array}$} \\
\cline { 2 - 5 } & $g=1 \mathrm{~mm}$ & $g=3 \mathrm{~mm}$ & $g=1 \mathrm{~mm}$ & $g=3 \mathrm{~mm}$ \\
\hline \multirow{2}{*}{ MITROMAG } & $263 \mathrm{~kg}$ & $395 \mathrm{~kg}$ & $298 \mathrm{~kg}$ & $553 \mathrm{~kg}$ \\
\cline { 2 - 5 } & $20.2 \mathrm{k} \$$ & $24.2 \mathrm{k} \$$ & $19.5 \mathrm{k} \$$ & $21.0 \mathrm{k} \$$ \\
\hline \multirow{2}{*}{ LTM } & $1231 \mathrm{~kg}$ & $1601 \mathrm{~kg}$ & $3100 \mathrm{~kg}$ & $3169 \mathrm{~kg}$ \\
\cline { 2 - 5 } & $90.5 \mathrm{k} \$$ & $88.0 \mathrm{k} \$$ & $51.8 \mathrm{k} \$$ & $61.3 \mathrm{k} \$$ \\
\hline
\end{tabular}




\section{CONCLUSIONS}

It was shown in this paper that for high-force, low-speed reciprocating applications, the electromechanical energy conversion system formed by integration of a TROMAG and a rotary PM machine can far surpass a conventional direct drive linear PM machine in terms of weight, volume, and material cost. When accounting for the efficiency-tied cost of electricity, MITROMAG can still be much more cost effective than LTM if mechanical losses of TROMAG can be kept reasonably small. The margin of advantage of MITROMAG over PM LTM is very large: at $100 \mathrm{kN}$ force with $1 \mathrm{~m}$ stroke, a MITROMAG can be an order of magnitude lighter and more compact than a PM LTM and three times less costly at once. It was also observed that while a rotary IPM can be a large portion of the overall weight of a MITROMAG, the cost of the MITROMAG is mainly determined by cost of its TROMAG. Moreover, the cost associated with losses of a TROMAG can be the largest contributor to a MITROMAG cost.

The MITROMAG, however, may lose its advantage over PMLTM for applications that require a smaller force and a longer stroke. Depending on the force and the stroke for which the system is designed, if the stroke of a MITROMAG turns out to be much larger than its active length, then the advantage of the MITROMAG over the PM LTM can diminish especially in terms of the overall cost.

\section{ACKNOWLEDGMENT}

The authors would like to thank ANSYS for the generous support of the Maxwell software, and Dr. David Meeker for free distribution of the FEMM software.

\section{REFERENCES}

[1] K. Atallah and D. Howe, "A novel high-performance magnetic gear," IEEE Trans. Magn., vol. 37, pp. 2844-2846, 2001.

[2] N. W. Frank and H. A. Toliyat, "Analysis of the Concentric Planetary Magnetic Gear With Strengthened Stator and Interior Permanent Magnet Inner Rotor," IEEE Trans. Ind. Appl., vol. 47, pp. 1652-1660, 2011.

[3] P. O. Rasmussen, T. V. Frandsen, K. K. Jensen, and K. Jessen, "Experimental Evaluation of a Motor-Integrated Permanent-Magnet Gear," IEEE Trans. Ind. Appl., vol. 49, pp. 850-859, 2013.

[4] K. Atallah, J. Rens, S. Mezani, and D. Howe, "A Novel Pseudo DirectDrive Brushless Permanent Magnet Machine," IEEE Trans. Magn., vol. 44, pp. 4349-4352, 2008.

[5] K. T. Chau, Z. Dong, J. Z. Jiang, L. Chunhua, and Z. Yuejin, "Design of a Magnetic-Geared Outer-Rotor Permanent-Magnet Brushless Motor for Electric Vehicles," IEEE Trans. Magn., vol. 43, pp. 2504-2506, 2007.

[6] N. W. Frank and H. A. Toliyat, "Gearing ratios of a magnetic gear for wind turbines," in Proc. IEEE International Electric Machines and Drives Conference (IEMDC), 2009, pp. 1224-1230.

[7] J. Linnin, K. T. Chau, and J. Z. Jiang, "A Magnetic-Geared Outer-Rotor Permanent-Magnet Brushless Machine for Wind Power Generation," IEEE Trans. Ind. Appl., vol. 45, pp. 954-962, 2009.

[8] L. Wenlong, G. Shuang, W. Diyun, and Z. Xiaodong, "Design of a linear magnetic-geared free-piston generator for series hybrid electric vehicles," in Proc. IEEE Vehicle Power and Propulsion Conference (VPPC), 2010, pp. 1-6.

[9] D. Yi, K. T. Chau, C. Ming, and W. Yubin, "A linear magnetic-geared permanent magnet machine for wave energy generation," in Proc. International Conference on Electrical Machines and Systems (ICEMS), 2010, pp. 1538-1541.
[10] L. Wenlong, K. T. Chau, and J. Z. Jiang, "Application of Linear Magnetic Gears for Pseudo-Direct-Drive Oceanic Wave Energy Harvesting," IEEE Trans. Magn., vol. 47, pp. 2624-2627, 2011.

[11] H. T. Faus, "Magnetic transmission," US Patent 2,371,511, 1945.

[12] S. Pakdelian and H. A. Toliyat, "Trans-Rotary Magnetic Gear for Wave Energy applicaion," in Proc. IEEE Power and Energy Society General Meeting, 2012, pp. 1-4.

[13] R. K. Holm, N. I. Berg, M. Walkusch, P. O. Rasmussen, and R. H. Hansen, "Design of a Magnetic Lead Screw for Wave Energy Conversion," IEEE Trans. Ind. Appl., vol. 49, pp. 2699-2708, 2013.

[14] J. Wang, K. Atallah, and W. Wang, "Analysis of a Magnetic Screw for High Force Density Linear Electromagnetic Actuators," IEEE Trans. Magn., vol. 47, pp. 4477-4480, 2011.

[15] S. Pakdelian, N. W. Frank, and H. A. Toliyat, "Principles of the TransRotary Magnetic Gear," IEEE Trans. Magn., vol. 49, pp. 883-889, 2013.

[16] S. Pakdelian, N. W. Frank, and H. A. Toliyat, "Analysis and design of the trans-rotary magnetic gear," in Proc. IEEE Energy Conversion Congress and Exposition (ECCE), 2012, pp. 3340-3347.

[17] S. Pakdelian and H. A. Toliyat, "Design aspects of the Trans-Rotary Magnetic Gear," in Proc. 38th Annual Conference on IEEE Industrial Electronics Society (IECON), 2012, pp. 1720-1725.

[18] S. Pakdelian and H. A. Toliyat, "Magnetic design aspects of the ransRotary Magnetic Gear," IEEE Trans. Energy Convers., vol. 30, no. 1, pp. 41-50, 2015.

[19] Genetic Optimization System Engineering Toolbox (GOSET) 2.6. Available: https://engineering.purdue.edu/ECE/Research/Areas/PEDS/go_system_ engineering_toolbox

[20] J. E. Heikkinen and S. Pakdelian, "Rotordynamics of a Trans-Rotary Magnetic Gear Rotor," in Proc. International Mechanical Engineering Congress and Exposition (ASME), 2013, pp. V04BT04A046V04BT04A046.

[21] S. Pakdelian and H. A. Toliyat, "Dynamics of the Trans-Rotary Magnetic Gear for point-absorbing wave energy application,", Accepted for presentation in IEEE Energy Conversion Congress and Exposition (ECCE), 2014.

[22] H. Polinder, B. C. Mecrow, A. G. Jack, P. G. Dickinson, and M. A. Mueller, "Conventional and TFPM linear generators for direct-drive wave energy conversion," IEEE Trans. Energy Convers., vol. 20, pp. 260-267, 2005.

[23] Y. Deshpande, H. A. Toliyat, S. S. Nair, J. Dhinagar, S. Immadisetty, and S. Nalakath, "Design aspects of high torque density permanent magnet motor for electric two wheeler applications," submitted to IEEE Tans. Ind. Appl., 2014.

[24] D. M. Ionel, M. Popescu, M. I. McGilp, T. J. E. Miller, S. Dellinger, and R. J. Heideman, "Computation of core losses in electrical machines using improved models for laminated steel," IEEE Trans. Ind. Appl., vol. 43, no. 6, pp. 1554-1564, 2007.

[25] J. K. Tangudu, T. M. Jahns, and T. P. Bohn, "Design, analysis and loss minimization of a fractional-slot concentrated winding IPM machine for traction applications," in Proc. IEEE Energy Conversion Congress and Exposition (ECCE), 2011, pp. 2236-2243.

[26] D. Staton, A. Boglietti, and A. Cavagnino, "Solving the More Difficult Aspects of Electric Motor Thermal Analysis in Small and Medium Size Industrial Induction Motors," IEEE Trans. Energy Convers., vol. 20, pp. 620-628, 2005.

[27] H. Polinder, M. E. C. Damen, and F. Gardner, "Linear PM Generator system for wave energy conversion in the AWS," Energy Conversion, IEEE Transactions on, vol. 19, pp. 583-589, 2004.

[28] J. Prudell, M. Stoddard, E. Amon, T. K. A. Brekken, and A. Von Jouanne, "A Permanent-Magnet Tubular Linear Generator for Ocean Wave Energy Conversion," IEEE Trans. Ind. Appl., vol. 46, pp. 2392$2400,2010$.

[29] J. wang and D. Howe, "Design optimization of radially magnetized, iron-cored, tubular permanent-magnet machines and drive systems," IEEE Trans. Magn, vol. 40, pp. 3262-3277, 2004.

[30] B. Deok-je, H. Polinder, J. A. Ferreira, and H. Seung-soo, "Structural mass minimization of large direct-drive wind generators using a buoyant rotor structure," in Proc. IEEE Energy Conversion Congress and Exposition (ECCE), 2010, pp. 3561-3568. 


\section{BIOGRAPHIES}

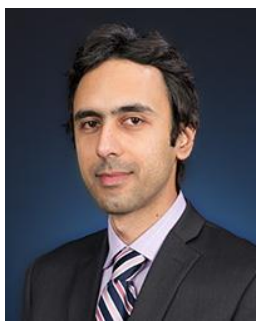

Siavash Pakdelian (S'11) received the B.S. degree from Sharif University of Technology, Tehran, Iran, in 2003, the M.Sc. degree from University of Tehran, Iran, in 2006, and Ph.D. degree from Texas A\&M University, College Station, in 2014, all in electrical power engineering. He is now a Research Assistant Professor with the Department of Electrical and Computer Engineering, University of Illinois at Chicago. His research interests include analysis, design, and control of electro-mechanical energy conversion systems, with a focus on magnetic gearing.

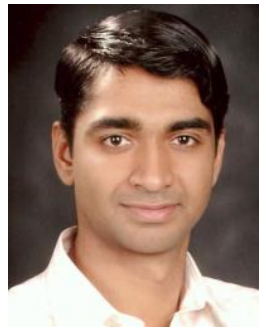

Yateendra Deshpande (S'12) Yateendra B. Deshpande (S'12, M'15) received his B.Tech. and M.Tech. degrees from Indian Institute of Technology, Madras in 2007 and his doctorate from Texas A\&M University in 2014, all in electrical engineering. From 2007 to 2009, he worked in the Advanced Engineering Group of TVS Motor Company, India as an electric machine design engineer for electric and hybrid electric vehicles. During his Ph.D., he also worked with Texas Instruments, Dallas for solving the harder problems of low speed operation and standstill position detection for SPMSM. He is currently a postdoctoral researcher at Texas A\&M University with the Advanced Electric Machines and Power Electronics Laboratory. His research interests include design optimization and modeling and control of synchronous electric machine.

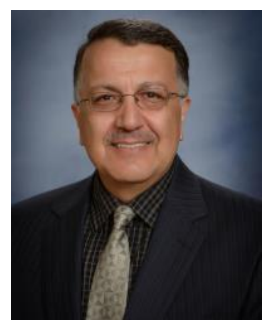

Hamid A. Toliyat (S'87-M'91-SM'96-F'08) received the B.S, degree from Sharif University of Technology, Tehran, Iran in 1982, the M.S. degree from West Virginia University, Morgantown, WV in 1986, and the Ph.D. degree from University of Wisconsin-Madison, Madison, WI in 1991, all in electrical engineering. Following receipt of the $\mathrm{Ph} . \mathrm{D}$. degree, he joined the faculty of Ferdowsi University of Mashhad, Mashhad, Iran as an Assistant Professor of Electrical Engineering. In March 1994 he joined the Department of Electrical and Computer Engineering, Texas A\&M University where he is currently Raytheon endowed professor of electrical engineering.

Dr. Toliyat has received the prestigious Nikola Tesla Field Award from IEEE in 2014, the Cyrill Veinott Award in Electromechanical Energy Conversion from the IEEE Power Engineering Society in 2004, Patent and Innovation Award from Texas A\&M University System Office of Technology Commercialization's in 2007, TEES Faculty Fellow Award in 2006, Distinguished Teaching Award in 2003, E.D. Brockett Professorship Award in 2002, Eugene Webb Faculty Fellow Award in 2000, and Texas A\&M Select Young Investigator Award in 1999. He has also received the Space Act Award from NASA in 1999, and the Schlumberger Foundation Technical Awards in 2001 and 2000.

Dr. Toliyat was an Editor of IEEE Transactions on Energy Conversion. $\mathrm{He}$ was Chair of the IEEE-IAS Industrial Power Conversion Systems Department of IEEE-IAS, and is a member of Sigma Xi. He is a fellow of the IEEE, the recipient of the 2008 Industrial Electronics Society Electric Machines Committee Second Best Paper Award as well as the recipient of the IEEE Power Engineering Society Prize Paper Awards in 1996 and 2006 and the 2006 IEEE Industry Applications Society Transactions Third Prize Paper Award. Prof. Toliyat has supervised more than 80 graduate students, post docs and research engineers, published over 420 technical papers, presented more than 80 invited lectures all over the world, and has 16 issued and pending US patents. He is the author of DSP-Based Electromechanical Motion Control, CRC Press, 2003, the co-editor of Handbook of Electric Motors - $2^{\text {nd }}$ Edition, Marcel Dekker, 2004, and the co-author of Electric Machines - Modeling, Condition Monitoring, and Fault Diagnosis, CRC Press, Florida, 2013.

He was the General Chair of the 2005 IEEE International Electric Machines and Drives Conference in San Antonio, Texas. Dr. Toliyat is a Professional Engineer in the State of Texas. 